\title{
Discussion About the Relationship Between Human Alienation and Contemporary Mass Culture*
}

\author{
Menghu Wang \\ Lanzhou City University \\ Lanzhou, China 730070
}

\begin{abstract}
Alienation means that people and their target world are in an opposite state. There is an inseparable internal relationship between mass culture and human alienation. The alienation of human beings has created conditions for the prosperity of mass culture, and in turn the mass culture has deepened the alienation of human beings. At the same time, mass culture has become another type of ideology in the contemporary era; at least it has carried out a kind of "alternative ideology" function to the public in a cultural form.
\end{abstract}

Keywords-alienation; mass culture; entertainment; othering

\section{INTRODUCTION}

In his "Economics Philosophy Manuscript in 1844", Marx pointed out that dissimilation is the opposite of the human being and its target world. The means of life has become the purpose of life. He said: "The more power a worker consumes in labor, the more powerful he has created to oppose his own and the alien world of objects world. The poorer he himself and his inner world, the less he owns." $[1]^{\mathrm{P} 52}$ In fact, human alienation is a negative impact that is inevitable with the refinement of social production division and the commercialization of economic forms. Because "the separation of capital, rent and labor is fatal to workers", [1] ${ }^{\mathrm{P} 7}$, the root of human alienation lies in the separation of labor and capital.

Marx pointed out that the separation of capital and labor and the division of labor in the production of commodity economy make the individual "turned into a one-sided person, causing him to develop abnormally and limit him." $[2]^{\mathrm{P} 514}$ In this state, the laborer in labor, "not to affirm himself, but to deny himself, not to feel happy, but to feel unfortunate." $[1]^{\mathrm{P} 50}$ As a result, an individual cannot claimi for himself the whole of his essence in a comprehensive manner as a whole man. [1] ${ }^{\mathrm{P} 83}$ and he can only become onesided and alienated people.

\section{The MANIFESTATION OF HUMAN ALIENATION}

This alienation state is manifested in the following aspects: First, the separation of labor and needs. Under the conditions of commodity economy, laborers do not work to produce products that can be directly enjoyed by them. The

*Fund: Research Project of Higher Education in Gansu Provincial Education Department "Research on "Reader" Magazine in Multidimensional Perspective" No.: 2015A-120 purpose of labor is to occupy other people's labor by occupying labor wages. Therefore, for the laborer, labor is not the purpose of the laborer, but the means to achieve another purpose. The labor and labor purposes are in a state of serious separation. "Therefore, this kind of labor is not a means of satisfying a need, but just satisfying those needs other than labor." $[1]^{\mathrm{P} 55}$ Second, the opposition between labor purposes and labor results. In the mode of production of commodity economy, the purpose of labor of workers is to maximize the right to control the labor of others, that is, to obtain the maximum freedom to control the external world through wages, but the premise of the realization of this purpose is the possibility that the laborer gives up the right to freely choose the form of labor and turns himself into a single-part, single-sided, one-sided producer to qualify for the initial purpose of labor. That is, the purpose of labor is for freedom, and the labor process itself is conditional on the loss of freedom of workers. "The more they want to make more money, the more they have to sacrifice their time and completely renounce all freedom and engage in slave labor for greed." $[1]^{\mathrm{P} 9}$ Third, the opposition between workers and labor products. The reason why human production differs from the production of animals is that people can freely control their own labor objects. "An animal's products directly belong to its flesh, and people are free to face their own products." [1] ${ }^{\mathrm{P} 58}$ Originally, since people are conscious beings, people should be free to control their own production behaviors and their products, but in the increasingly refined and commoditized production patterns of social division, people have the ability to produce certain products. However, they are unable to govern these products. The usual result is that producers are on the contrary dominated by their own products. For example, workers produce machines, which in turn simplify people into fixed parts on the production line, repeating the same old ways day after day. Fourth, it is the separation of demand and consumption. In the alienation state of the human being, the product consumed by the laborer is not something he produces himself, not what he needs, but what the market can provide to him and what he can afford, that is, what the laborer finally consumes is not necessarily what he needs, but only what the market provides to him. He has the right to choose whether to consume or not, but he cannot choose the consumption objects he needs.

It should be said that in addition to the reasons of Marx's "Economics Philosophy Manuscript in 1844", such as private ownership, social division of labor, separation of capital and 
labor, and so on, there are also "technical rationality" trends in modern times. Marcuse pointed out in his book "One Dimensional Man": "Technical advancement extends to the entire domination and coordination system, creating forms of life (and power) that reconcile the forces opposing the system and defeat and reject all protests in the name of the historical prospect of freedom from servitude and domination." [3] ${ }^{\mathrm{P} 4}$ If in Marx's view, the social and industrial capitalist production methods lead to the alienation of human existence, and then in Marcuse's view, the manipulation of "mass culture" by technological ideology leads to the alienation of human thought, forming the so-called "one dimensional person". Marcuse believes that the control of personal thoughts and behaviors in modern society is stricter than in any previous era. This kind of control mainly relies on technical ideology, that is, bourgeois cultural industry or contemporary mass culture formed by the combination of "technological rationality" trend of thought and hedonistic value orientation, thus making people in reality become "one dimensional person" who have lost the ability of thinking, reflecting, criticizing and surpassing consciousness.

\section{HUMAN ALIENATION HAS CREATED CONDITIONS FOR THE PROSPERITY OF MASS CULTURE}

If the market economy, civil society and hedonism create the basis of value orientation for the existence of mass culture, then the overall alienation of human beings (state of existence and ideology) dispels the obstacles of the subject for the existence and prosperity of mass culture.

First, the core part of alienation is the loss of human subjectivity. In the state of alienation, people do not freely and consciously occupy and dominate the object world and its labor products, but the laborers are in turn dominated by the object world, that is, people are not only in the position of being dominated in material relations, but also in the position of being dominated in thought and idea by others, completely losing their own conscious, free beingness, and being alienated into the conditions for the existence of other beings. Mass culture is characterized by public participation and public acceptance. The loss of human subjectivity is manifested by the popularization of individual thoughts, concepts and behaviors. Therefore, the weakening of individual subjectivity is the first step that human alienation opens up for mass culture.

Second, it is the falsification of needs. There is no false question in the perfect state of existence of a person, but the need for a person in a state of alienation is often created by society rather than by his own true desire. For example, the pursuit of various brand-name products by people in the modern era is mostly due to the false demand created by TV commercials. For the falsification of needs, Marcuse has proposed that "in the final analysis, what is the real need and the false need must be answered by all individuals themselves." [3] $]^{7}$ That is, if the subject is in a state of being manipulated and infused, then his needs are false. "The need to impose on individuals on the basis of specific social interests, the need to perpetuate hardship, aggression, suffering and injustice is a 'false' need." And "most of the current needs, such as rest, entertainment, conducting oneself in society and consumption according to the advertising, loving and hating the love and hate of others are all in the category of false needs." [3] ${ }^{\mathrm{P} 6}$ The reason why mass culture can be accepted and even addicted is because people's need for this culture is a need created by mass culture and this kind of need is implied to be a very fashionable one for people, which is a demanding force for the mass culture to prosper enduringly.

Third, it is the othering of the individual consciousness. The popularization of society is based on the disappearance of personal consciousness and even the alienation. In this state of alienation, what everyone strives to pursue is to turn themselves into "other people" — the standardized and modeled other people. Therefore, the alienated modern people seem to follow such a principle:" I wear what others wear; I play what others play; I laugh in the way others laugh; I cry in the way others cry". All of these individuals are completely alienated and flattened - all people are others, and others are all people; a group of people is like a person, and one is like all persons. The othering and flattening of the individual removes the biggest obstacle for the expansion of mass culture: everyone's - from eating and dressing to talking and behaving, from crying posture to laughing tune, are all the same and uniform. Alienation has caused individuals to lose their uniqueness. Critical spirit and critical ability are out of the question. What the public can do is to accept and consume. No matter what the mass culture sells, no one in the public will stand up against and criticize it.

\section{The DEEPENING EFFECT OF MASS CULture ON THE ALIENATION OF HUMAN BEINGS}

Mass culture is a kind of culturally colored commodity that is mass-produced and copied through modern large industrial production lines under the conditions of market economy. Its use value is to satisfy the needs of the mass consumers for sensory entertainment and spiritual comfort. The exchange value is the price in the market transaction. "The reason why the mass literature cannot be regarded as literature is that it produces the culture completely as a commodity, and the profit is its purpose." $[4]^{\mathrm{P} 10}$ But on the other hand, as a literary product, it is not entirely a commodity. As far as its "value" is concerned, as a commodity, its value is reflected in the consumption of its general labor and means of production, that is, its market price is determined by the price of the labor and means of production in which it is produced; as a literary work, its "value" is not completely embodied by market prices. Its nature is spiritual. Material (medium) is only the carrier of its "value" rather than "value" itself. In a word, "the mass entertainment culture has two sides. On the one hand, it belongs to culture and acts on people's spiritual senses; on the other hand it belongs to economy, it is commodity, and it completely follows the principle of market efficiency." [4] ${ }^{\mathrm{P} 9}$

The mass culture is under the banner of "the culture of the masses", and what is sent out to the public is only what it wants to sell, not what the public wants. Judging from the relationship between the production and consumption of mass literature and art, on the surface, according to the 
general economic principle, certain market consumption needs determine the emergence of certain production content, and therefore, according to this principle, some commentators generally defend the production of mass culture in this way: it is the cultural demand of the mass that determines the production content of the mass culture. In fact, in the relationship between the production and consumption of mass culture, the consumption content of the masses is not determined by the individualized taste of the masses, but "concocted" and hyped up by the producers of mass culture. The masters of mass culture, through all kinds of overwhelming advertisements, omnipresent media, such as fantasy film scene, repeatedly and subtly instill to the public some aesthetic tastes and values, and teach them what is fashion, what is taste, what is a famous brand and what is popular, etc., therefore, the consumption of the public is thus created and cultivated by the mass culture. "On the surface, the masses are shaping the mass culture, but in reality the masses are shaped by mass culture. The true leadership of the 'new trend' is not the public, but the mass culture from the mass media to advertising movies. "[5] ${ }^{\mathrm{P} 19}$ Therefore, mass culture is not a culture owned by the public, but the passive acceptance by the masses of a certain form of culture produced by mass media in the era of commodity economy.

Mass literature gives the public a kind of false (spiritual) freedom. The core of freedom is the ability (can) to say "no", and mass culture will make the public identify with everything that exists. "A unique role of mass culture is to make people accustomed to affirming and accepting existing things." [5] ${ }^{\mathrm{P} 20}$ From the point of view of the public's choice of consumption of mass culture, the public has the freedom to choose whether to consume or not. But what content is specifically consumed is not chosen by the public. What mass culture offers the public to choose from is what they want to sell, not what the public really need. In this consumer behavior that seems to be free but indeed forced, the mass turn into the "replicas" with same taste, same interest, same judgment as well as same living methods of mass media culture due to the commodity culture copied by the mass culture. It seems to be free, but it is actually suppressing. On the surface, it displays individuality, in fact, it is obliterating personality. It can be said that mass culture has become another type of ideology in the contemporary era; at least it has carried out a kind of "alternative ideology" function to the public in the form of a culture. Mass culture will eventually lose the lowest level of cultural critique and reflective ability that society may have. Under this circumstance, the individual's spiritual freedom does not exist at all. Although the individual can obtain greater political and religious freedom than any era in the mass society, this external freedom cannot in any way save the othering of individual from the loss of the inner spiritual freedom - He exists as a human being, and he does not exist as a single human.

\section{CONCLUSION}

Modern mass culture is a historical product of the combination of market economy and modern media. It is characterized by commercialization, modeling, sense and replicability. In an era of diversification, mass culture uses its ubiquitous influence to shape and standardize the audience-unified and othering ideals, aesthetic interests, value standards, and so on. Although mass culture has the function of dispelling authority, leisure and entertainment, and comforting in the heart, there is also an output problem of ideas behind the narrative attitude of mass culture, which does not involve problems and ignores reality. On the surface, the mass consumption culture is rich and colorful, and varied in forms, and in fact, this seemingly diverse culture has obvious homogeneity and potential coercion. From the perspective of consumption effects, the masses shaped by this homogenous cultural product will become a consumer group that is randomly instructed by mass culture. As a result, mass culture has become an alternative ideological cultural force, which has become a manipulation culture of the public.

\section{REFERENCES}

[1] Marx. Economics Philosophy Manuscript in 1844 [M]. Translation by the Central Compilation and Translation Bureau, Beijing: People's Publishing House; 2000. (in Chinese)

[2] Marx. The Complete Works of Marx and Engels. Volume 3 [M]. Translation by the Central Compilation and Translation Bureau, Beijing: People's Publishing House; 2003. (in Chinese)

[3] [United States] Herbert Marcuse. One Dimensional Man — The Study of Ideology in Developed Industrial Society [M]. Liu Ji translation, Shanghai: Shanghai Century Publishing Group; 2006. (in Chinese)

[4] Zhang Fa. Three Issues on Chinese Literature and Art Situation in the 1990s [J]. Literature and Art Controversy, 1994 (1). (in Chinese)

[5] Zhang Rulun. On Mass Culture[J]. Journal of Fudan University, 1994(3). (in Chinese) 